Bioscientia Medicina: Journal of Biomedicine \& Translational Research

Journal Homepage: www.bioscmed.com

\title{
Comparison of the Effectiveness 3\% Tranexamic Acid Cream Versus 4\% Hydroquinone Cream for Treatment of Epidermal Type Melasma
}

\section{Hartika Ketty Marpaung ${ }^{1 *}$. Theresia L. Toruan ${ }^{2}$. Yuli Kurniawati ${ }^{3}$}

${ }^{1}$ Department of Dermatology and Venereology. Dr. Mohammad Hoesin General Hospital. Sriwijaya University. Medical Research Unit. Sriwijaya University

${ }^{2}$ Fellow of Departmenr of Dermatology and Venereology. Dr. Mohammad Hoesin General Hospital

${ }_{3}^{3}$ Fellow Students. Department of Ophthalmology. Faculty of Medicine. Sriwijaya University. Indonesia.

\section{A R T I C L E I N F O \\ Keywords: \\ 3\% TA cream \\ 4\% HQ cream \\ mMASI score \\ Mexameter ${ }^{\circledR}$ \\ *Corresponding author: \\ Hartika Ketty Marpaung \\ E-mail address: \\ tikaketty@yahoo.com}

All authors have reviewed and approved the final version of the manuscript.

https://doi.org/10.32539/bsm.v5i3.221

\begin{abstract}
A B S T R A C T
Background: Melasma is an acquired hypermelanosis in areas that are exposed to sun. especially in face. Severity of melasma is measured using modified Melasma Area Severity Index (mMASI) and Melanin Index (MI). Hydroquinone (HQ) is an effective drug and also a gold standard in terms of melasma treatment. However. the drawback of hydroquinone is the treatment duration which is quite long. the occurence of side effects. and also recurrence potential. Several recent studies shows that one of the anti-pigmentation agent options. the tranexamic acid (TA). is able to prevent melanocyte activation. The results of various studies found that the use of TA showed a significant improvement in MASI scores. Objective: To compare the effectivity of $3 \%$ TA cream with $4 \%$ HQ cream as an alternative therapy in epidermal type melasma treatment. Methods: A double-blind. matched. randomized clinical trial was conducted during July 2019 until August 2019 at Dr. Mohammad Hoesin General Hospital Palembang. Subjects were divided into two groups. The first group. consists of 30 participants. get $3 \%$ TA cream; and the second group. consists of 30 participants. get $4 \%$ HQ cream. Subjects who fulfilled the inclusion criteria was included through a simple randomization. Study subjects wer given random cream pot (with label A or B on it) according to the result of simple randomization. Finally. every subjects' melasma severity was measured using mMASI and mexameter ${ }^{\circledR}$. Results: There were differences in terms of baseline. $4^{\text {th }}$ weeks and $8^{\text {th }}$ weeks after treatment mMASI scores in 3\% TA and $4 \%$ HQ group. At $8^{\text {th }}$ week. the mMASI score the 3\% TA group was lower than 4\% HQ group. There was no differences in baseline. $4^{\text {th }}$ weeks and $8^{\text {th }}$ after treatment MI between the two groups. Melanin index for $3 \%$ TA group was lower than 4\% HQ group. Conclusion: Three-percent TA cream and 4\% HQ cream is effective in decreasing mMASI score and MI in epidermal type melasma. There were differences in terms of the mMASI score during the 8 th week after treatment between $3 \%$ TA and $4 \%$ HQ group.
\end{abstract}

\section{Introduction}

Melasma is an acquired hypermelanosis in areas that are exposed to sun. especially in face. ${ }^{1}$ Lesions are brownish macular or patches. symmetrical. firm borders and irregular edges. ${ }^{2.3}$ Melasma often occur in women with Fitzpatrick IV to VI skin type. especially those who live in an area with high sun exposure. ${ }^{4}$ Severity of melasma is measured with modified melasma area severity index (mMASI). The mMASI scoring system was validated and reliable in 2017 to measure the severity of melasma. ${ }^{5}$ Other than mMASI. severity of melasma can be measured objectively using mexameter ${ }^{\circledR} .6$

Hydroquinone (HQ) is one of anti-pigmentation agents which inhibit the conversion of dihydroxyphenylalanine (DOPA) to melanin through tyrosinase inhibition and induces melanocyte 
breakdown by inhibiting the synthesis of Ribonucleic Acid (RNA) and Deoxyribonucleic Acid (DNA). Hydroquinone is an effective drug for the treatment of melasma. needs long term treatment duration. but has side effects and potential recurrence. According to the level and quality evidence for the treatment of melasma. HQ is included in level II and the quality of evidence is A. ${ }^{7}$

Tranexamic Acid (TA) is the inhibitor of plasmin supressing angiogenesis and neovascularization induced by fibroblast growth factor (FGF) a potent melanocyte growth factor. ${ }^{8}$ Increased plasmin results in the release of intracellular arachidonic acid (AA). Arachidonic acid is a prostanoid precursor increasing the level of a-melanocyte stimulating hormone (a-MSH) which activates melanin synthesis in melanocyte. Plasmin is also important in the process of releasing FGF in melanogenesis. Recently. the usage of TA as anti-pigmentation agents to prevent melanocyte activation. has spread as a treatment for melasma. ${ }^{9}$

\section{Material and Methods}

This study will determine the comparison between the effectiveness of TA 3\% with HQ 4\% with a randomized double blind clinical trial design in patients with epidermal type melasma. This study was conducted from July to September 2019 in the DV polyclinic of Cosmetic Dermatology Division of Dr. Mohammad Hoesin Hospital in Palembang. The inclusion criteria were female patients with melasma. above 20 years old with epidermal type obtained from the result of wood's lamp and dermoscope examination. On wood's lamp examination. epidermal type melasma is characterized by accentuation of melasma lesions. because the wood's lamp rays are absorbed by basal or suprabasal melanin deposits. whereas in dermoscopic examination. epidermal type melasma shows a darkbrown homogenic pigmented color and a regular pigmentary network.

Sampling technique used was simple random sampling. During research. there were 60 patients who met the inclusion criteria. Simple randomization of study participants was determined in two groups. 30 patients are included in TA 3\% group and 30 patients in HQ 4\% group.

\section{Results}

Total study participants were 60 people. The mean age of study participants in TA $3 \%$ group was $44.53 \pm$ 7.592 years with an age-range of 28 to 59 years; whereas in HQ 4\% group the mean age was $42.86 \pm$ 8.321 years with an age-range of 26 to 61 years. Statistical analysis shows that there were no differences in age between TA 3\% group and HQ 4\% group $(p=0.426)$. Patient's distribution by age. occupation and education group as well as melasma pattern is shown in table 1.

In TA $3 \%$ group. majority of melasma patients are civil servants (53.3\%). whereas in HQ 4\% group are private employee. Statistical analysis result show that there were no significant differences by occupation between patient in TA 3\% group and HQ 4\% group $(p=0.144)$. Based on the work of TA 3\% group and HQ $4 \%$ group; it was found that the majority of patient's last educations were high school and statistical results were significant ( $p=0.120)$.

The majority of melasma pattern in the two groups were centrofacial melasma pattern. Statistical analysis result show that there were no differences in melasma pattern between TA 3\% group and HQ 4\% group and the result is significant $(\mathrm{p}=0.380)$.

The mMASI score of patient with melasma was measured three times. which was before treatment (beseline). at week 4 and week 8 after treatment. Data distribution of mMASI score are shown in table 2.

There is one difference in mMASI score at baseline. week 4 and week 8 after treatment in TA 3\% group and HQ 4\% group. In fact there is a significant decrease in mMASI score at each measurement in both TA $3 \%$ group and HQ4\% group (Table 3).

There was no difference in mMASI score at baseline between the two groups. There was a difference in mMASI score at week 4 and week 8 between the two groups. mMASI score in TA $3 \%$ group is lower than in HQ 4\% group (Table 4).

Melanin index of patients with melasma was 
measured using Mexameter ${ }^{\circledR}$ three times that is before treatment. at week 4 and week 8 after treatment. (Table 5)

Study result shows that there is no difference in IM at baseline. week 4 and week 8 after treatment between the two groups. Melanin index of TA 3\% group is lower than HQ 4\% group. (Table 7)

Table 1. Distribution of patients by age. occupation. education and melasma pattern

\begin{tabular}{|c|c|c|c|}
\hline \multirow{2}{*}{ Characteristics } & \multicolumn{2}{|c|}{ Groups } & \multirow[b]{2}{*}{$p$ value } \\
\hline & $\begin{array}{l}\text { TA } 3 \% \\
(n=30)\end{array}$ & $\begin{array}{l}\text { HQ 4\% } \\
\text { (n = 28) }\end{array}$ & \\
\hline \multicolumn{4}{|l|}{ Age (years) } \\
\hline - $\quad$ Mean \pm SD & $44.53 \pm 7.592$ & $42.86 \pm 8.321$ & $0.426^{*}$ \\
\hline - $\quad$ Median $(\min -\max )$ & $44(28-59)$ & $42.5(26-61)$ & \\
\hline \multicolumn{4}{|l|}{ Profession n (\%) } \\
\hline - Housewife & $6(20.0)$ & $7(25.0)$ & $0.144^{* *}$ \\
\hline - $\quad$ Private employees & $8(26.7)$ & $13(46.4)$ & \\
\hline - Government employees & $16(53.3)$ & $8(28.6)$ & \\
\hline \multicolumn{4}{|l|}{ Education } \\
\hline - $\quad$ Primary school & $0(0)$ & $1(3.6)$ & \\
\hline - Junior high school & $0(0)$ & $2(7.1)$ & \\
\hline - High school & $13(43.3)$ & $18(64.3)$ & $0.120^{* *}$ \\
\hline - $\quad$ D3 & $12(40.0)$ & $6(21.4)$ & \\
\hline $\begin{array}{ll}-\mathrm{S} 1 \\
\mathrm{~S} 2\end{array}$ & $3(10.0)$ & $1(3.6)$ & \\
\hline$-\quad N \angle$ & $2(6.7)$ & $0(0)$ & \\
\hline \multicolumn{4}{|l|}{ Melasma pattern } \\
\hline - Malar & $5(16.7)$ & 5 (17.9) & \\
\hline - Mandibular & $2(6.7)$ & $0(0)$ & $0.380 * *$ \\
\hline - Centrofacial & $23(76.7)$ & $23(82.1)$ & \\
\hline
\end{tabular}

${ }^{*}$ Independent T $\cdot p=0.05$

${ }^{* *}$ Uji Chi Square. $p=0.05$

Table 2. Distribution of mMASI scores $(p>0.05)$

\begin{tabular}{lclll}
\hline Group & $\begin{array}{c}\text { Total of patient } \\
(\mathbf{n})\end{array}$ & Measuring & Average \pm SD & p value \\
\hline TA3\% & 30 & Baseline & $3.307 \pm 2.789$ & 0.000 \\
& & Week-4 & $2.263 \pm 1.788$ & 0.000 \\
& & Week-8 & $1.483 \pm 1.134$ & 0.000 \\
\hline HQ 4\% & Baseline & $3.504 \pm 1.527$ & 0.200 \\
& 28 & Week-4 & $2.850 \pm 1.457$ & 0.200 \\
& & Week-8 & $2.250 \pm 1.290$ & 0.200 \\
\hline
\end{tabular}

Kolmogorov smirnov, $p=0.05$ 
Table 3.MASI score for the TA group 3\% and the HQ group 4\%

\begin{tabular}{|c|c|c|c|c|}
\hline Group & $\begin{array}{c}\text { Total of patient } \\
\text { (n) }\end{array}$ & Measuring & $\begin{array}{l}\text { Average } \pm \text { SD } \\
\text { mMASI Score }\end{array}$ & $p$ value \\
\hline TA 3\% & 30 & $\begin{array}{ll}\text { - } & \text { Baseline - weeks-4 } \\
\text { - } & \text { Baseline - weeks -8 } \\
\text { - } & \text { Weeks-4 - weeks -8 }\end{array}$ & $\begin{array}{l}3.307 \pm 2.263 \\
2.307 \pm 1.483 \\
2.263 \pm 1.483\end{array}$ & $\begin{array}{l}0.00{ }^{*} \\
0.00{ }^{*} \\
0.000^{*}\end{array}$ \\
\hline HQ 4\% & 28 & $\begin{array}{ll}\text { - } & \text { Baseline - weeks -4 } \\
\text { - } & \text { Baseline - weeks-8 } \\
\text { - } & \text { Weeks-4 - weeks-8 }\end{array}$ & $\begin{array}{l}3.504 \pm 1.527 \\
3.504 \pm 2.850 \\
2.850 \pm 2.250\end{array}$ & $\begin{array}{l}0.000 * * \\
0.000 * * \\
0.000 * *\end{array}$ \\
\hline
\end{tabular}

*Wilcoxon test. $p=0.05$

**Independent $T$ Test. $p=0.05$

Table 4. Comparison of the mMASI score of the 3\% TA group and the 4\% HQ group

\begin{tabular}{|c|c|c|c|}
\hline \multirow[b]{2}{*}{ Measuring } & \multicolumn{2}{|c|}{ Group } & \multirow[b]{2}{*}{$p$ value } \\
\hline & $\begin{array}{l}\text { TA } 3 \% \\
\text { (n = 30) }\end{array}$ & $\begin{array}{c}\text { HQ 4\% } \\
\text { (n = 28) }\end{array}$ & \\
\hline Baseline & $3.307 \pm 2.789$ & $3.504 \pm 1.527$ & $0.131^{*}$ \\
\hline Weeks-4 & $2.263 \pm 1.788$ & $2.850 \pm 1.457$ & $0.061^{* *}$ \\
\hline Weeks-8 & $1.483 \pm 1.134$ & $2.250 \pm 1.290$ & $0.002 *$ \\
\hline
\end{tabular}

*Wilcoxon test. $p=0.05$

**Independent $T$ Test. $p=0.05$

Table 5 Distribution of melanin index scores $(p>0.05)$

\begin{tabular}{llcc}
\hline Group & Measuring & Average \pm SD & p value \\
\hline TA 3\% & Baseline & $299.55 \pm 69.23$ & 0.001 \\
& week-4 & $276.05 \pm 60.26$ & 0.068 \\
& week-8 & $256.08 \pm 59.19$ & 0.009 \\
\hline HQ 4\% & Baseline & $362.59 \pm 196.97$ & 0.000 \\
& week-4 & $330.01 \pm 183.93$ & 0.000 \\
& week-8 & $270.43 \pm 72.341$ & 0.200 \\
\hline
\end{tabular}

Kolmogorov smirnov test, $\mathrm{p}=0.05$

Table 5. The value of the melanin index in the TA group 3\% and the HQ group 4\%

\begin{tabular}{|c|c|c|c|}
\hline Group & $\begin{array}{l}\text { Total of } \\
\text { patient } \\
\text { (n) }\end{array}$ & Duration of measurement & p value \\
\hline TA 3\% & 30 & $\begin{array}{ll}\text { - } & \text { Baseline - week-4 } \\
\text { - } & \text { Baseline - week-8 } \\
\text { - } & \text { Week-4-week-8 }\end{array}$ & $\begin{array}{l}0.00{ }^{*} \\
0.000 * \\
0.000 *\end{array}$ \\
\hline HQ 4\% & 28 & $\begin{array}{ll}\text { - } & \text { Baseline - week-4 } \\
\text { - } & \text { Baseline - week-8 } \\
\text { - } & \text { Week-4 - week-8 }\end{array}$ & $\begin{array}{l}0.00{ }^{*} \\
0.00{ }^{*} \\
0.00{ }^{*}\end{array}$ \\
\hline
\end{tabular}

*Wilcoxon test. $p=0.05$ 
Table 7 .The melanin index score of the 3\% TA group and 4\% HQ group

\begin{tabular}{|c|c|c|c|}
\hline \multirow[b]{2}{*}{ Measuring } & \multicolumn{2}{|c|}{ Group } & \multirow[b]{2}{*}{ p value } \\
\hline & $\begin{array}{l}\text { TA } 3 \% \\
(n=30)\end{array}$ & $\begin{array}{l}\text { HQ 4\% } \\
(n=28)\end{array}$ & \\
\hline Baseline & $299.55 \pm 69.23$ & $362.59 \pm 196.97$ & $0.102 *$ \\
\hline Week-4 & $276.05 \pm 60.26$ & $330.01 \pm 183.93$ & $0.168 *$ \\
\hline Week-8 & $256.08 \pm 59.19$ & $270.43 \pm 72.341$ & $0.446^{*}$ \\
\hline
\end{tabular}

*Wilcoxon test. $p=0.05$

\section{Discussion}

Melasma is an aquired hypermelanosis. in the area exposed to sunlight. especially the face. ${ }^{1}$ Melasma can occur in women and men. mostly in women in productive age. A cross sectional study by Hexel et al. in 2013 to 953 melasma patients in Brazil showed a ratio of female melasma patients compared to men as large as 39:1.10 The greater female ratio in melasma patients was thought because of the influence of female sex hormones (estrogen and/or progesteron) in the pathogenesis of melasma. Some study reported that estrogen increases the expression of $\operatorname{Trp}-1$. and $\operatorname{Trp}-2$. and the activity of tyrosinase in the culture of human melanocytes. Estrogen evidently increases melanin synthesis in healthy human melanocyte culture through activation of cAMP protein kinase pathway and the upregulation of tyrosinase expression as well as microopthalmiaassociated transcription factors (MITF). ${ }^{11}$

The mean age of melasma patients is 43.7 years with a range of 26 to 61 years old. The mean age of melasma patients in this study is in accordance with a retrospective study by Goh and Dlova in 2014 to 205 melasma patients in Singapore. which reported that the mean age of melasma patients was 42.3 years old. But the result of this study is greater than the study in India in 2009 to 312 melasma patients which reported that the mean age of melasma patients was 33.45 year. As well as with an observational study by Ali et al. in 2013 which reported the mean age of patients with melasma was 29.7 years. ${ }^{14}$ A retrospective study by Gazi et al. in 2017 reported the mean age of patients with melasma 30.1 years with a range of 20 to 49 years old.15 In addition. clinical trials conducted by Nasrollahi et al. in 2019 to 22 female patients with melasma in Iran reported the mean age of melasma patients was 39.20 years. ${ }^{16}$ The greater mean age in this study may be caused by the fact that almost $25 \%$ of melasma patients in this study were more than 50 years old that the mean age was increased. According to statistical test. there is no difference in age. between TA 3\% group (mean age 44.5 years) and HQ 4\% group (mean age 42.86). This proves that the treatment results are not affected by age so both groups can be compared.

Majority of patients occupation was civil servant (TA $3 \%$ group) and private employee (HQ 4\%). According to statistical tests the results show there is no difference in occupation between patients in the TA $3 \%$ group and the HQ 4\% group. This proves that the treatment result are not affected by occupation so both groups can be compared. Meanwhile melasma patients educations are high school students both in TA 3\% group and HQ $4 \%$ group. According to statistical tests there are no difference in education between patients in TA $3 \%$ group and HQ 4\% group. This proves that treatment results are not affected by education so both groups can be compared. Cross sectional study by Arora et al. in 2016 in India to 156 melasma patients. reported that education level with the highest amount in melasma patients was elementary students (30.8\%) and $75 \%$ of patients were housewife. A cross sectional study by Leeyaphan et al. in 78 melasma patients in Thailand reported that there are no relationship between melasma with patient's education and occupation. ${ }^{17}$

The majority of melasma patterns in study patients 
were centrofacial. According to statistical test there is no difference in melasma pattern among patients in TA $3 \%$ group and HQ 4\% group. This proves that treatment results were not affected by melasma pattern so both groups can be compared. The result of this study is in accordance with previous literature and research. which stated that distribution of melasma lesions often found was centrofacial. ${ }^{2}$ A prospective study by Guinot et al. in 2010 in Tunisia to 197 melasma patients also reported that $76 \%$ of melasma patients have a distribution pattern of centrofacial.18 A retrospective study by Tamega etl al. in 2012 reported that the most common distribution of melasma was centrofacial. as large as $69.2 \% .19$

In this study mMASI and IM were measured before treatment. week 4 and week 8 after treatment. The result of mMASI score in this study shows a difference between before and after treatment. Twenty nine of thirty $(96.7 \%)$ of patient's mMASI score was decreased at week 4 after TA 3\% treatment. In 30 of 30 (100\%) patients. mMASI score was decreased at week 8 after TA 3\% treatment. In addition. there was a difference in IM score before and after treatment. IM score decreases at each treatment. Twenty nine of 30 (96.7\%) of patient's IM score was decreased at week 4 after TA 3\% treatment and 30 of 30 (100\%) patient's IM score was decreased after at week 8 after TA 3\% treatment compared to before treatment. This proves that TA 3\% are effective in decreasing mMASI and IM score in melasma at week 4 and week 8 after treatment both subjectively and objectively. This result is in accordance with a study by Ayuthaya et al. in 2012 to 21 melasma patients in Thailand. which reported that mMASI was significantly decreased after TA treatment $(p<0.000)$. In addition. IM score in 18 of 20 patients was decreased after 12 weeks of therapy.20 A study by Laothaworn et al. in 2018 to 25 patients in Thailand reported that mMASI score was decreased 1.14 points in 4 weeks after therapy $(p=0.011)$ and 1.18 points in 8 weeks after therapy $(p=0.023)$. In addition. IM score was significantly decreased as large as 12.79 points in 4 weeks after TA and laser treatment $(p=0.016) .{ }^{21} \mathrm{~A}$ study by Janney et al. in 2019 to 100 melasma patients in India reported that mMASI score was decreased at week 4. 8. and 12 after TA $5 \%$ treatment $(p<0.05) .22$

Tranexamic acid prevents pigmentation induced by UV through reduction of melanocyte tyrosinase activity. Melanocyte tyrosinase activity disrupts the structure of plasminogen and prevents the binding of plasminogen to the binding site of lysin in keratinocytes. Consequently free AA is reduced and the ability to produce prostaglandin is lacking. Prostaglandin is an inflamatory mediator of melanogenesis. ${ }^{23}$ TA action in angiogenesis through plasmin is also important in the process of melasma. Inhibition of Sc-uPA pathway may be another mechanism of TA reducing hyperpigmentation.24.25 Maeda and Tomita stated that TA inhibits melanin synthesis in melanocyte by dysrupting the interaction between melanocyte and keratinocyte through inhibition of plasminogen or plasmin system. ${ }^{26}$ Zhang et al. stated that TA can inhibit melanogenesis by disrupting the catalytic reaction of tyrosinase. ${ }^{27}$ In addition. it was found that TA structure is similar with tyrosin causing a competitive effect that can inhibit tyrosinase activity. 27.28

Hydroquinone is a hidroxyphenol that competes with tyrosin. a natural substrate of tyrosinase when faced with a number of catalyst. Hydroquinone can inhibit the conversion of DOPA to melanin by inhibiting tyrosinase enzyme. This study proves that there is a difference in mMASI score before and after treatment. mMASI score decreases in 26 out of 28 (92.9\%) patients. mMASI score decreases at week 4 after HQ 4\% treatment and 28 out of 28 patients (100\%) have a decreasing mMASI score at week 8 after treatment of HQ 4\%. IM score was decreased at each measurement. IM score in 27 of 28 (96.4\%) patients was decreased at week 4 after HQ 4\% therapy. IM score in 28 of 28 $(100 \%)$ samples was decreased at week 8 after therapy compared to before therapy. This proves that HQ $4 \%$ is effective in decreasing IM score at week 4 and week 8 after therapy both subjectively and objectively. The study by Nasrollahi et al. in 2019 to 22 patients in Iran reported that mMASI was decreased from 3.37 to 2.6 in week $4(p=0.000)$ and was decreased again to 2.4 in week $8(p=0.010)$ after application of Januluma ${ }^{\circledR}$ cream containing a mixture of HQ 4\%. ${ }^{16}$ The study by Janney 
et al. also compares the effectivity of HQ 3\% and TA 5\%. but TA level in this study is lower. ${ }^{22}$ Common HQ side effects depend on the dosage and duration of application. Side effects include irritation. erythema. irritant or allergic contact dermatitis and transient halo hypochromia in the treated area. ${ }^{29}$ In this study. erythema side effect was seen in two patients.

The mMASI and IM score in both groups was compared. result in week 4 after treatment shows that there is no difference of mMASI and IM score in both groups. But. in week 8 after treatment there is a difference in mMASI score between TA 3\% group and HQ 4\% group. mMASI score in TA 3\% group is lower compared to $\mathrm{HQ} 4 \%$ group. IM score in TA 3\% group is lower compared to HQ 4\% but not significant. This study is in accordance with the study by Janney et al. in 2019 to 100 melasma patients in India comparing TA 5\% and HQ 3\%. which proved a decreasing percentage of mMASI score of $27 \%$ in TA $5 \%$ group and $26.7 \%$ in HQ 3\% group. and there was no difference between both groups $(p>0.05) .{ }^{22} \mathrm{HQ}$ therapeutic dosage can cause irritation. The involvement of immune mediator acts in the clinical implementation causing irritation. Disruption in the barriers of epidermis causes cytokine release. one of them is IL-1. that leads to irritation reaction and induce barrier repair mechanism. Interleukin-1 acts in the skin irritation process. IL-1 originates from keratinocytes that are damaged during interactions between the irritant and the epidermal barrier. ${ }^{30}$

It can be concluded that application of TA $3 \%$ is more effective compared to $\mathrm{HQ} 4 \%$ application after 8 weeks of treatment. mMASI score and IM score were decreased. so application of $\mathrm{TA} 3 \%$ is more recommended to be given to melasma patients considering the decrease of mMASI and IM score are greater in week 4 and week 8 after treatment. apart from that no side effects were found.

This study has been conducted using the appropriate methods. but still have limitations such as the amount of study participants were limited and hospital based. that this study can yet be generalized in the wider population. Apart from that. side effects were measured subjectively using forms that were filled by patients. Side effects should have been assessed using tools. so the result can be more accurate such as colorimeter. spectrophotometer or Doppler Flowmetry laser. This study can be used as a basis for further population- or multicenter-based study.

\section{Conclusion}

TA 3\% and HQ 4\% cream are effective in decreasing mMASI and IM score in epidermal type melasma both subjectively and objectively at week 4 and 8 after treatment $(p=0.000)$ and side effects in the form of erythema were only found in two patients in HQ 4\% group.

\section{References}

1. Lapeere H. Boone B. Schepper SD. Verhaeghe E. Gele MV. Ongenae K. et al. Hypomelanoses and hypermelanoses. In: Wolff K. Goldsmith LA. Katz SI. Gilchrest BA. Paller AS. Lefel DJ. editors. Fitzpatrick's Dermatology in General Medicine. $8^{\text {th }}$ ed. New York: McGraw Hill; 2012. p.804-26.

2. Chang MW. Disorders of hyperpigmentation. In: Bolognia JL. Jorizzo JL. Schaffer JV. editors. Dermatology. $3^{\text {rd }}$ ed. Philadelphia: Elesveier Saunders; 2012. p.1049-74.

3. Rathi SK. D'Souza P. Epidemiology of melasma. In: Lahiri K. Charttejee CM. Sarkar R. editors. Pigmentary Disorders. A Comprehensive Compedium. New Delhi: Jaypee Brother Medical; 2014. p. 282-6.

4. Geel NV. Speeckaert K. Acquired pigmentary disorders. In: Griffiths C. Barker J. Bleiker T. Chalmers R. Cramer D. editors. Rook's Textbook of Dermatology. 9th ed. London: John Wiley \& Sons; 2012. p.88.1-56.

5. Pandya AG. Hynan LS. Bhore R. Riley FC. Guevara IL. Grimes P. et al. Reliability assessment and validation of the melasma area and severity index (MASI) and a new modified MASI scoring method. J Am Acad Dermatol 2011;64:78-83.

6. Park ES. Na JI. Kim SO. Huh CH. Youn SW. 
Park KC. Aplication of a pigment measuring device-Mexameter ${ }^{\circledR}$-for the differential diagnosis of vitiligo and nevus depigmentosus. Skin Res Technol 2006;298-302.

7. Sarma N. Poojary SA. Rathi S. Kumaran S. Nirmal B. Felicita J. Sarkar R. et al. Evidancebased review grade of recommendation. and suggested treatment recommendations for melasma. Indian Dermatol Online $\mathrm{J}$ 2017;8(6):406-422.

8. Ebrahimi B. Naeini FF. Topical tranexamic acid as a promising treatment for melasma. J Res Med SCI 2014;19:753-7.

9. Poojary S. Minni K. Tranexamic acid in melasma: A review. Pigmentary Disorder 2015;2(12);1-4.

10. Hexsel D. Lacerda DA. Cavalcante AS. Machado CAS. Kalil CL. Ayres EL. et al. Epidemiology of melasma in Brazilian patients:

a multicenter study. Int $\mathrm{J}$ Dermatol. 2014;53(4):440-4.

11. Handel AC. Lima PB. Tonolli VM. Miot LD. Miot HA. Risk factors for facial melasma in women: a case control study. $\mathrm{Br} \mathrm{J}$ Dermatol 2014;171(3):588-94.

12. Sarkar R. Garg VK. Sonthalia S. Gokhale N. Melasma update. Indian Dermatol Online $\mathrm{J}$ 2014;5(4):426-35. 